\title{
INTER-RELAÇÃO BIOMASSA VEGETAL SUBTERRÂNEA- ESTABILIDADE DE AGREGADOS-EROSÃO HÍDRICA EM SOLO SUBMETIDO A DIFERENTES FORMAS DE MANEJO(1)
}

\author{
Leandro Bochi da Silva Volk ${ }^{(2)} \&$ Neroli Pedro Cogo ${ }^{(3)}$
}

\begin{abstract}
RESUMO
O aumento da biomassa vegetal subterrânea e da estabilidade dos agregados do solo pelo seu manejo adequado aumentam sua capacidade para infiltrar água da chuva e resistir à erosão hídrica. Baseado nesta premissa, foi realizado um estudo de erosão em campo, sob chuva simulada, na Estação Experimental Agronômica da Universidade Federal do Rio Grande do Sul - EEA/UFRGS, em Eldorado do Sul (RS), no verão de 2003/2004, utilizando um experimento de manejo do solo com 7,5 anos de duração. O objetivo da pesquisa foi investigar relações entre variáveis de manejo e de erosão, relacionadas à história de uso e manejo do solo e suas condições físicas superficiais momentâneas, criadas por tratamentos de seu preparo e de cobertura por resíduo cultural, os quais foram aplicados imediatamente antes da realização de testes de erosão com chuva simulada. Utilizou-se um Argissolo Vermelho distrófico típico, com textura superficial francoargilo-arenosa e declividade média de $0,115 \mathrm{~m} \mathrm{~m}^{-1}$. Foram estudadas quatro seqüências culturais, com ou sem preparo (gradagem) e cobertura (resíduo cultural) do solo. Realizaram-se três testes de erosão com chuva simulada, cada um na intensidade de $64 \mathrm{~mm} \mathrm{~h}^{-1}$ e duração de $1,5 \mathrm{~h}$, usando o aparelho simulador de braços rotativos. Avaliaram-se a massa de raízes mortas das plantas, o diâmetro médio ponderado de agregados do solo, a taxa constante de infiltração de água no solo e a perda total de água e de solo por erosão. A infiltração de água no solo foi maior e, inversamente, a perda de água menor no solo recém-mobilizado (superfície solta e rugosa) do que no solo não-mobilizado (superfície firme e praticamente lisa), mesmo o primeiro estando descoberto e o segundo tanto coberto quanto descoberto, com diferenças entre as seqüências culturais. No solo não-mobilizado e coberto, a perda foi pequena em todas as seqüências culturais, enquanto no solo
\end{abstract}

\footnotetext{
(1) Parte da tese de Doutorado do primeiro autor, apresentada no PPG Ciência do Solo Universidade Federal do Rio Grande do Sul - UFRGS, realizada com recursos financeiros do Projeto CNPq-PRONEX/Solos e do Auxílio "grant"/CNPq, e com o apoio de bolsistas de iniciação científica dos Programas PIBIC-CNPq/UFRGS, CNPq e FAPERGS. Recebido para publicação em setembro de 2007 e aprovado em julho de 2008 .

(2) Professor Adjunto, Departamento de Agronomia, Campus Regional de Umuarama, Universidade Estadual de Maringá - UEM. Av. Colombo 5790, CEP 87020-900 Maringá (PR). Ex-Bolsista CAPES. E-mail: lbsvolk@uem.br

(3) Professor Associado, Departamento de Solos, Faculdade de Agronomia, Universidade Federal do Rio Grande do Sul - UFRGS. Av. Bento Gonçalves 7712, Caixa Postal 15100, CEP 91501-970 Porto Alegre (RS). Bolsista do CNPq. E-mail: neroli@ufrgs.br
} 
descoberto, tanto não-mobilizado quanto recém-mobilizado, ela foi pequena somente naquelas seqüências culturais que propiciaram altos valores de massa de raízes mortas das plantas e de diâmetro médio ponderado de agregados do solo. No solo recém-mobilizado e descoberto, a diminuição da perda de solo também se deveu à rugosidade superficial criada pelo preparo. As relações da perda total de água e da perda total de solo, com a massa de raízes mortas das plantas e com o diâmetro médio ponderado de agregados do solo, foram significativas a 5 \%.

Termos de indexação: chuva simulada, seqüência cultural, preparo do solo, cobertura do solo, infiltração de água, perda de água, perda de solo.

\title{
SUMMARY: INTERRELATION OF UNDERGROUND PLANT BIOMASS WITH SOIL AGGREGATE STABILITY AND RAINFALL EROSION OF A SOIL UNDER DIFFERENT MANAGEMENTS
}

\begin{abstract}
Increasing underground plant biomass and soil aggregate stability by application of adequate management practices enhances the quality in terms of water infiltration and erosion resistance. Based on this premise, an erosion study using simulated rainfall was carried out in the field, at an experimental station of the Universidade Federal do Rio Grande do Sul - EEA/UFRGS), in Eldorado do Sul, Rio Grande do Sul State, Brazil, in the summer of 2003/2004, in a 7.5 year soil management experiment. The purpose of the research was to investigate relationships between management and erosion variables, related to a given history of soil use and management and to the momentary, surface physical conditions created by tillage and residue-cover treatments, applied immediately before erosion tests. A sandy clay loam Ultisol with $0.115 \mathrm{~m} \mathrm{~m}^{-1}$ average slope steepness was used. Four crop sequences were studied in no-till, under tillage (disking) and under mulch-cover (crop residue). Three erosion tests of simulated rainfall were performed with a rotating-boom rainfall simulator, each of them at a rainfall intensity of $64 \mathrm{~mm} \mathrm{~h}^{-1}$ during $1.5 \mathrm{~h}$. The root mass of dead plants, soil aggregate mean-weight diameter, soil and water loss were determined. In the freshly-tilled soil (loose and rough surface) water infiltration in the soil was higher, contrasting with the lower water loss than in the untilled soil (firm and smooth surface), even though the former was bare and the later was either bare or mulched. There were also differences among the crop sequences. Soil loss was small in all crop sequences in the untilled, mulch-covered soil, while in the bare, untilled or freshlytilled soil it was only small in the crop sequences that produced high amounts of dead plant root mass and where the soil aggregate mean-weight diameter was high. In the freshlytilled, bare soil with high values of these two latter variables, the decrease in soil loss was due to the surface roughness created by tillage. The relationships of total water loss (declining) and total soil loss with dead plant root mass and with soil aggregate meanweight diameter were significant at $5 \%$.
\end{abstract}

Index terms: simulated rainfall, crop sequence, soil tillage, soil cover, water infiltration, water loss, soil loss.

\section{INTRODUÇÃO}

Fundamentalmente, a magnitude do processo de erosão hídrica pluvial do solo depende de uma combinação da capacidade da chuva de causar erosão (erosividade da chuva) e da habilidade do solo de resistir à ação da chuva (erodibilidade do solo). A habilidade do solo de resistir à ação da chuva é determinada por vários fatores, mas, principalmente, pela sua erodibilidade intrínseca, pela topografia do terreno e pelas práticas de manejo usadas no processo de produção vegetal. A erodibilidade intrínseca do solo refere-se a sua vulnerabilidade ou suscetibilidade à erosão, sendo a recíproca da resistência ao referido processo. Ela resulta da interação de fatores químicos, físicos, biológicos e mineralógicos do solo. A composição granulométrica, a mineralogia, o teor de matéria orgânica, a estrutura e a permeabilidade do solo são as características que mais se relacionam com sua erodibilidade intrínseca (Wischmeier \& Smith, 1978; Hudson, 1995). 
O uso e o manejo adequados do solo constituem o principal meio de aumentar sua resistência à erosão, seja hídrica ou eólica. Os métodos de preparo do solo e de semeadura das culturas e as práticas conservacionistas de suporte (cultivo em contorno, faixas de cultura em contorno e terraços agrícolas, entre outros) são os componentes de manejo que mais determinam a resistência de um solo à erosão hídrica pluvial, uma vez que eles impõem condições físicas à superfície do solo que vão fortemente interferir na ação dos agentes erosivos (Wischmeier, 1973; Cogo et al., 1983, 1984; Hudson, 1995; Volk et al., 2004).

A proteção à superfície do solo pode ser dada pela parte aérea (dossel) das plantas e, ou, pelos seus restos culturais (quando eles são deixados na lavoura), ambos contrapondo-se à ação erosiva da chuva e, desta forma, dissipando e, ou, diminuindo, parcial ou totalmente, a energia cinética originada do processo de queda de suas gotas. Os resíduos culturais também contribuem para a melhoria da estrutura do solo e servem de obstáculo físico ao livre escoamento superficial ou enxurrada (Wischmeier \& Smith, 1978; Cogo, 1981; Amado et al., 1989).

O aumento da biomassa vegetal subterrânea (resíduos culturais incorporados e, ou, raízes - vivas ou mortas) e da estabilidade dos agregados do solo pelo seu manejo adequado aumentam sua qualidade para resistir à erosão hídrica (Cogo et al., 2003; Volk, 2006) . A eficácia das raízes das plantas na redução da erosão hídrica pluvial do solo pode se manifestar de duas formas: a primeira diz respeito à ação mecânica exercida pelas plantas, fisicamente ligando as partículas de solo entre si e agindo como barreira ao livre movimento superficial de água e de solo; a segunda refere-se às substâncias orgânicas exsudadas pelas raízes vivas ou em processo de decomposição, as quais atuam como agente ligante no processo de aglutinação das partículas do solo, além de servirem de fonte de energia para os microrganismos que o habitam, resultando em melhorias na estrutura do solo e, decorrente disso, em melhor capacidade para infiltrar água da chuva e resistir à erosão hídrica pluvial. Entretanto, é necessário considerar que as plantas se diferenciam quanto à influência de suas raízes na melhoria da estrutura do solo, principalmente os grandes grupos de gramínea e leguminosa. Devido sua maior capacidade de regeneração, maior produção de matéria seca e maior densidade do sistema radicular, as gramíneas têm recebido atenção especial no que se refere à agregação do solo, pelo efeito que exercem na aglutinação de suas partículas e na estabilização dos agregados resultantes. Por sua vez, as leguminosas destacam-se pela natureza de sua matéria seca, com baixa relação C/ $\mathrm{N}$, portanto de fácil decomposição pelos microrganismos do solo, o que também vai contribuir no processo de aglutinação de suas partículas (Tisdall \& Oades, 1982). Dessa forma, a formação, a estabilidade e a qualidade dos agregados do solo alteradas pelo seu uso e manejo normalmente apresentam boa correlação com a quantidade de raízes em sua massa (Silva, 1993).

A estabilidade dos agregados do solo é de suma importância no controle da erosão hídrica pluvial, não só diante das ações de impacto das gotas da chuva e cisalhante da enxurrada, mas, também, diante de seu rápido umedecimento (Yoder, 1936). Um solo que contém agregados pouco resistentes ao umedecimento rápido será facilmente erodido quando exposto à ação da chuva (Yoder, 1936), além de ficar sujeito ao fenômeno do selamento superficial, uma vez que as partículas desagregadas do solo podem obstruir seus poros e limitar a infiltração de água nele (Tisdall \& Oades, 1982; Le Bissonnais, 1996; Le Bissonnais \& Arrouyas, 1997). Este fato facilita a desagregação e o transporte de solo pela enxurrada (Albuquerque et al., 2000).

Este trabalho foi realizado com o objetivo de investigar as relações entre a massa de raízes mortas das plantas e o diâmetro médio ponderado de agregados do solo e os processos de infiltração de água, escoamento superficial e erosão hídrica pluvial em solo não-mobilizado (superfície consolidada e praticamente lisa), com ou sem cobertura por resíduo cultural, e em solo recém-mobilizado (superfície solta e rugosa), sem cobertura por resíduo cultural, utilizando um experimento de manejo do solo com 7,5 anos de duração, constituído de seqüências culturais variadas, implantadas no método de semeadura direta.

\section{MATERIAL E MÉTODOS}

O estudo foi desenvolvido na Estação Experimental Agronômica da Universidade Federal do Rio Grande do Sul - EEA/UFRGS, localizada no $\mathrm{km} 146$ da rodovia BR 290, município de Eldorado do Sul (RS), na região fisiográfica da Depressão Central, que, segundo a classificação de Köeppen, apresenta clima do tipo "Cfa" - subtropical úmido com verão quente. O solo da área experimental é classificado como Argissolo Vermelho distrófico típico (Streck et al., 1999; Embrapa, 2006), apresentando textura superficial franco-argiloarenosa, horizontes diagnósticos A moderado e B textural, profundidade e drenagem moderadas, declividade média de $0,115 \mathrm{~m} \mathrm{~m}^{-1}$ e profundidade efetiva inferior a $0,80 \mathrm{~m}$ (Lopes, 1984). No quadro 1 são apresentados os valores de algumas características físicas e o teor de matéria orgânica do solo em questão, obtidos na sua condição original de campo nativo, em fevereiro de 1995, por Badelucci (1997).

A pesquisa foi realizada nas condições reais de campo, porém sob chuva simulada. Para isso, empregou-se o aparelho simulador de chuva de braços rotativos (Swanson, 1965), o qual simultaneamente asperge água, na forma de gotas, sobre duas parcelas experimentais (Figura 1). Neste trabalho, cada par de parcelas experimentais constituiu as repetições dos 
Quadro 1. Composição granulométrica, teor de matéria orgânica (MO), densidade global (Ds), porosidade total (P) e diâmetro médio ponderado (DMP) de agregados do solo em duas de suas camadas, avaliados na sua condição original de campo nativo, em fevereiro de 1995 (Badelucci, 1997)

\begin{tabular}{|c|c|c|c|c|c|c|c|}
\hline \multirow[b]{2}{*}{ Camada de solo } & \multicolumn{3}{|c|}{ Composição granulométrica } & \multirow[b]{2}{*}{ MO } & \multirow[b]{2}{*}{ Ds } & \multirow[b]{2}{*}{$\mathbf{P}$} & \multirow{2}{*}{ DMP } \\
\hline & Areia & Silte & Argila & & & & \\
\hline $\mathrm{cm}$ & 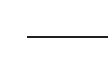 & 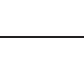 & -1 & - & $\mathrm{Mg} \mathrm{m}^{-3}$ & $\mathrm{~m}^{3} \mathrm{~m}^{-3}$ & $\mathrm{~mm}$ \\
\hline $\begin{array}{r}0-10 \\
10-20\end{array}$ & $\begin{array}{l}560 \\
550\end{array}$ & $\begin{array}{l}180 \\
140\end{array}$ & $\begin{array}{l}260 \\
310\end{array}$ & $\begin{array}{l}30 \\
21\end{array}$ & $\begin{array}{l}1,50 \\
1,66\end{array}$ & $\begin{array}{l}0,45 \\
0,38\end{array}$ & $\begin{array}{l}4,1 \\
3,5\end{array}$ \\
\hline
\end{tabular}

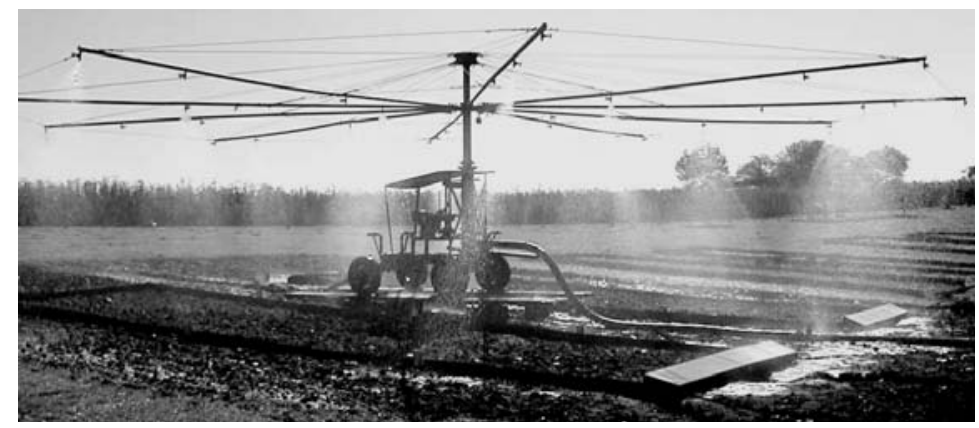

Figura 1. Aparelho simulador de chuva tipo de braços rotativos utilizado no estudo, simultaneamente operando sobre um par de parcelas experimentais de erosão.

tratamentos. As parcelas mediam 3,5 m de largura por $11,0 \mathrm{~m}$ de comprimento cada uma, com a maior dimensão sendo disposta no sentido do declive do terreno, distanciadas uma da outra de $3,5 \mathrm{~m}$, seguindo as recomendações de Embrapa (1975). Cada parcela foi delimitada por chapas galvanizadas com $2,0 \mathrm{~m}$ de comprimento por $0,20 \mathrm{~m}$ de largura cada uma, tendo sido cravadas $0,10 \mathrm{~m}$ no solo. Na porção inferior de cada parcela, foi instalada uma calha de coleta da enxurrada, acoplada a um cano plástico (tipo PVC, com 100 mm de diâmetro) com declividade suficiente para conduzir o escoamento superficial até uma pequena trincheira localizada $6,0 \mathrm{~m}$ abaixo. A cada três minutos eram medidas as vazões e coletadas amostras da enxurrada, utilizando-se, respectivamente, proveta graduada e cronômetro, e potes plásticos com capacidade de armazenagem de $1 \mathrm{~L}$.

Os tratamentos foram dispostos num delineamento próximo ao completamente casualizado (foram casualizadas apenas duas repetições de um dado tratamento, em dado par de parcelas experimentais) e envolveram tipos de seqüência cultural, métodos de preparo do solo e formas de manejo do resíduo cultural, assim especificados: (a) 4 anos de uso do solo com a sucessão aveia-preta (Avena strigosa) e milho (Zea mays, L), seguidos de 3,5 anos de uso com a sucessão aveia-preta e milheto (Pennisetum americanum), ambas em semeadura direta (4Av-Mi,SD/3,5AvMt,SD); (b) 4 anos sem cultivo e sem preparo do solo, seguidos de 3,5 anos de uso com a sucessão ervilhaca (Vicia sativa)-feijão miúdo (Vigna unguiculata), em semeadura direta (4Sc,SP/3,5Er-Fm,SD); (c) 7 anos sem cultivo e sem preparo do solo, seguidos de 0,5 ano de uso com aveia-preta, em semeadura direta (7Sc,SP/ $0,5 \mathrm{Av}, \mathrm{SD})$, e (d) 4 anos de uso do solo com a sucessão aveia-preta e milho, em semeadura direta, seguidos de 3,5 anos sem cultivo e sem preparo do solo (4Av$\mathrm{Mi}, \mathrm{SD} / 3,5 \mathrm{Sc}, \mathrm{SP})$.

As operações de preparo do solo e semeadura das culturas foram efetuadas no sentido do declive do terreno, conforme filosofia de obtenção do fator C cobertura e manejo dos modelos "USLE" e "RUSLE" de predição da erosão hídrica pluvial do solo (Wischmeier \& Smith, 1978; Renard et al., 1997).

Realizaram-se três testes de erosão com chuva simulada (T1, T2 e T3), cada um deles na intensidade constante de $64,0 \mathrm{~mm} \mathrm{~h}^{-1}$ e duração de $1,5 \mathrm{~h}$. O primeiro teste ( $\mathrm{T} 1$ ) foi realizado no final de outubro de 2003, um dia após a colheita da aveia-preta e da ervilhaca e a redistribuição uniforme de seus resíduos na superfície do solo, nas parcelas experimentais, sem ter sido realizado nenhum preparo de solo. Assim, neste teste (T1), a superfície do solo encontrava-se nãomobilizada (consolidada ou firme e praticamente lisa) e integralmente coberta (100\%, com resíduo cultural). Onze dias após a realização de $\mathrm{T} 1$, os resíduos culturais foram removidos da superfície do solo nas parcelas experimentais e, imediatamente, foi realizado o segundo teste de chuva (T2), também sem nenhum preparo de solo. Assim, neste teste (T2), a superfície do solo encontrava-se fisicamente igual à do teste $\mathrm{T} 1$, 
exceto pela cobertura por resíduo cultural, que estava ausente. Transcorridos vinte e seis dias da realização de T2, foi efetuado o terceiro e último teste de chuva (T3), porém, dessa vez, com o solo, imediatamente antes da aplicação da chuva, tendo sido preparado com grade leve (uma operação) na profundidade média de 0,15 m. Assim, neste teste (T3), a superfície do solo encontrava-se distinta da dos testes anteriores ( $\mathrm{T} 1 \mathrm{e}$ T2), ou seja, recém-mobilizada, portanto solta e com média a alta rugosidade, porém continuando desprovida de cobertura por resíduo cultural, igualmente como no segundo teste de chuva (T2). Para a análise de correlação com estas condições físicas (momentâneas) superficiais do solo, avaliaram-se características de solo e planta nas parcelas experimentais e de erosão no escoamento superficial.

Para a quantificação da massa dos resíduos culturais, eles foram removidos totalmente da superfície do solo nas parcelas experimentais, tendo sido pesados e retornados, uniformemente distribuídos, ao seu local de origem, tendo-se antes coletado amostras para a determinação de sua umidade, para posterior correção e expressão dos resultados em base de matéria seca (em estufa, a $60{ }^{\circ} \mathrm{C}$ ). Para a quantificação da massa de raízes mortas das plantas, foram coletadas amostras compostas de solo, cada uma constituída de três subamostras, na camada de 0 a $10 \mathrm{~cm}$ do solo, sendo uma na linha e duas nas entrelinhas, em dois locais dentro de cada parcela experimental. Para isso, utilizou-se trado de Fe de formato cilíndrico (4,7 cm de diâmetro), perfazendo cada subamostra o volume de $173,5 \mathrm{~cm}^{-3}$. Após a coleta, as amostras foram levadas para a casa de vegetação e postas a secar ao ar. Em prosseguimento, elas foram manualmente fragmentadas, lavadas e tamisadas em água, utilizando peneira com abertura de malha de $0,5 \mathrm{~mm}$, sendo posteriormente postas a secar em estufa, a $60{ }^{\circ} \mathrm{C}$.

Para a determinação do diâmetro médio ponderado (DMP) de agregados do solo, empregou-se a técnica de peneiramento úmido, sugerida por Yoder (1936). Para isso, foram coletadas amostras compostas de solo, cada uma constituída de três subamostras coletadas em pontos aleatórios dentro de cada parcela experimental e retiradas das camadas de 0 a 10 e 10 a $20 \mathrm{~cm}$ do solo. Essas amostras foram passadas, ainda com a sua umidade de campo, por um conjunto de peneiras, sobrepostas, com aberturas de malha de 7,96 e $4,76 \mathrm{~mm}$. Os agregados retidos na peneira com menor abertura de malha foram acondicionados em frascos plásticos, levados ao laboratório e postos a secar ao ar durante $72 \mathrm{~h}$. Após secos, os agregados foram novamente passados na peneira com abertura de malha de $4,76 \mathrm{~mm}$, descartando-se a porção que passava por ela. Em prosseguimento, foram colocados $50 \mathrm{~g}$ da amostra sobre um conjunto de peneiras com aberturas de malha de 4,$76 ; 2 ; 1 ; 0,5$ e $0,25 \mathrm{~mm}$, que foi submerso e deixado em repouso em água por $10 \mathrm{~min}$ e, em seguida, submetido à oscilação mecânica, também por 10 min, no movimento de 25 oscilações por minuto. A quantidade de agregados nas diferentes classes de tamanho foi obtida pela razão entre a massa deles retida em cada peneira e a massa total da amostra, com os resultados tendo sido expressos em termos de diâmetro médio ponderado (DMP) de agregados.

A cobertura do solo pelos resíduos culturais foi avaliada pelo método da corda marcada ou linha de transecção de pontos, segundo Hartwig \& Laflen (1978), enquanto a rugosidade superficial do solo criada pelo preparo, por meio do uso de um perfilômetro, semelhante ao descrito por Burwell et al. (1963), seguindo seu próprio método.

Para a avaliação das variáveis de erosão hídrica pluvial do solo (taxa constante de infiltração de água no solo, perda total de água e perda total de solo), foi adotado o método descrito em Cogo (1981).

Os resultados obtidos foram submetidos à análise da variância, empregando-se o teste de comparação de médias de Duncan, a $5 \%$, utilizando o programa computacional ESTAT (Sistema para Análises Estatísticas, v.2.0), desenvolvido pelo Pólo Computacional do Departamento de Ciências Exatas da FCAV/ UNESP, Jaboticabal (SP). Utilizando este mesmo programa, foram também efetuadas análises de regressão (linear e curvilinear), usando as variáveis de manejo do solo e erosão hídrica medidas no estudo. $\mathrm{O}$ modelo matemático usado para estabelecer correlação entre as variáveis foi baseado naquele que melhor descreveu o fenômeno da erosão, em relação à dada variável em particular. O grau de significância dos ajustes dos modelos matemáticos foi baseado no método proposto por Fischer \& Yates (1971). A interpretação dos dados, além dos resultados da análise estatística, foi baseada em teorias e conceitos desenvolvidos em estudos de mecânica da erosão hídrica pluvial do solo da literatura especializada.

\section{RESULTADOS E DISCUSSÃO}

No quadro 2 são apresentados os resultados da medição de algumas variáveis que denotam a condição física interna ou subsuperficial atual do solo, após ele ter saído da sua condição original de campo nativo, em maio de 1996, e passado a ser cultivado com culturas anuais em fileira, em sucessão contínua, que constituíram os tratamentos principais desta pesquisa. Observa-se que houve diferenças significativas entre as seqüências culturais no que se refere aos valores das variáveis investigadas (massa de raízes mortas secas, teor de matéria orgânica e diâmetro médio ponderado - DMP - de agregados) nas duas camadas avaliadas do solo. A seqüência cultural 4Av-Mi,SD/3,5Av-Mt,SD, além de criar boas condições físicas no solo, resultou na maior produção de massa de raízes mortas secas observada no estudo. Já as 
seqüências culturais $7 \mathrm{Sc}, \mathrm{SP} / 0,5 \mathrm{Av}, \mathrm{SD}$ (cultivo único de aveia-preta, no final do período experimental) e $4 \mathrm{Av}$ $\mathrm{Mi}, \mathrm{SD} / 3,5 \mathrm{Sc}, \mathrm{SP}$ (sem cultivo e sem preparo do solo nos últimos três anos e meio de condução do experimento) apresentaram os menores valores da variável em pauta nas duas camadas avaliadas do solo. A seqüência cultural 4Sc,SP/3,5Er-Fm,SD (sem cultivo e sem preparo do solo nos primeiros quatro anos de condução do experimento), apesar do baixo valor de massa de resíduo cultural seco (ervilhacaQuadro 3), apresentou valor de massa de raízes mortas secas correspondente a 70 \% do observado no seqüência cultural 4Av-Mi,SD/3,5Av-Mt,SD, nas duas camadas avaliadas do solo. No que se refere aos valores da razão massa de raízes mortas na camada de 10 a $20 \mathrm{~cm} / \mathrm{massa}$ de raízes mortas na camada de 0 a $10 \mathrm{~cm}$, eles foram baixos, comparados ao valor médio de 0,35 encontrado por Streck (1999) e Cogo \& Streck (2003) em pastagem nativa predominantemente constituída de gramíneas, dessecada um mês antes do início de seus estudos. Ressalta-se que os valores da referida razão, obtidos neste estudo, são bastante inferiores aos registrados nos arquivos computacionais do modelo "RUSLE" de predição da erosão hídrica (Renard et al., 1997), nos Estados Unidos da América, que variam de 0,80 a 0,75 . Neste caso, da mesma forma como argumentado por Streck (1999) e Cogo \& Streck (2003), as diferenças nos resultados podem ser atribuídas às diferenças no clima, tipo de solo e tipo de cultura entre os dois países.

No que diz respeito aos teores de matéria orgânica e valores de DMP (Quadro 2), eles foram sempre maiores na camada de 0 a $10 \mathrm{~cm}$ do solo. $\mathrm{O}$ acúmulo de matéria orgânica nesta camada era esperado, tendo em vista a grande quantidade de raízes mortas nela. Como também observado por Tisdall \& Oades (1982), os altos valores de massa de raízes e os altos teores de matéria orgânica resultaram em altos valores de diâmetro médio ponderado (DMP) de agregados.

No quadro 3 são apresentados os resultados da medição de algumas variáveis que denotam a condição física externa ou superficial do solo nas parcelas experimentais antes da realização dos testes de erosão com chuva simulada (T1, T2 e T3). Observa-se que a aveia-preta apresentou maior valor de massa seca de resíduo cultural do que a ervilhaca, independentemente do seu tempo no experimento, conseqüentemente, houve maior cobertura superficial do solo. Comparado ao valor médio obtido com a aveia-preta, a ervilhaca produziu $64 \%$ menos massa de resíduo cultural. Mesmo assim, ela ainda proporcionou elevada cobertura superficial do solo (82 \%). É interessante observar a persistência no tempo do resíduo cultural de milheto, o qual, mesmo após 12 meses sob a ação do clima e dos microrganismos, apresentou altos valores de matéria seca e equivalente percentagem de cobertura do solo. Esses resultados reafirmam a importância das gramíneas na produção de massa de resíduo cultural e sua equivalente percentagem de cobertura do solo, premissa básica nas práticas de controle da erosão hídrica de caráter vegetativo (Hudson, 1995). Devido à remoção dos resíduos das parcelas experimentais para a realização do segundo teste de chuva (T2), não havia cobertura superficial do solo no teste T2 e no teste T3.

No que diz respeito ao índice de rugosidade superficial do solo - IR (Quadro 3), ele foi baixo e similar em todos os tratamentos nos testes T1 e T2, pelo fato de o solo nestes testes ter estado sem mobilização, por sete anos, em função de ser cultivado em semeadura direta ou, então, não-cultivado e nãomobilizado. Devido à gradagem realizada no solo antes da realização do terceiro teste de chuva (T3), o índice de rugosidade superficial (IR) nas parcelas experimentais aumentou de 11 a 20 vezes, dependendo da seqüência cultural, comparado ao valor inicial antes do preparo do solo.

Na figura 2, são apresentados os resultados das variáveis de erosão hídrica avaliadas no estudo, nas diferentes situações investigadas. Em relação à taxa constante de infiltração de água no solo e à perda total

Quadro 2. Massa de raízes mortas secas, teor de matéria orgânica e diâmetro médio ponderado (DMP) de agregados em duas camadas do solo, antes da operação de seu preparo e da realização do primeiro teste de erosão com chuva simulada, nas seqüências culturais estudadas

\begin{tabular}{|c|c|c|c|c|c|c|c|}
\hline \multirow{2}{*}{ Seqüência cultural } & \multicolumn{3}{|c|}{ Massa seca de raízes mortas } & \multicolumn{2}{|c|}{ Teor de matéria orgânica } & \multicolumn{2}{|c|}{ DMP } \\
\hline & $0-10 \mathrm{~cm}$ & $10-20 \mathrm{~cm}$ & $\operatorname{Razão}^{(1)}$ & $0-10 \mathrm{~cm}$ & $10-20 \mathrm{~cm}$ & $0-10 \mathrm{~cm}$ & $10-20 \mathrm{~cm}$ \\
\hline & \multicolumn{3}{|c|}{$\mathrm{Mg} \mathrm{ha}^{-1}$} & \multicolumn{2}{|c|}{$\longrightarrow \mathrm{g} \mathrm{kg}^{-1} \longleftarrow$} & \multicolumn{2}{|c|}{$-\mathrm{mm}$} \\
\hline $4 \mathrm{Av}-\mathrm{Mi}, \mathrm{SD} / 3,5 \mathrm{Av}-\mathrm{Mt}, \mathrm{SD}$ & $13,5^{(2)} \mathrm{a}$ & $1,3 \mathrm{a}$ & 0,10 & $30 \mathrm{a}$ & $22 \mathrm{a}$ & $4,06 \mathrm{a}$ & $2,59 \mathrm{a}$ \\
\hline $4 \mathrm{Sc}, \mathrm{SP} / 3,5 \mathrm{Er}-\mathrm{Fm}, \mathrm{SD}$ & $8,0^{(3)} \mathrm{b}$ & $0,8 \mathrm{~b}$ & 0,10 & $28 \mathrm{ab}$ & $22 \mathrm{a}$ & $3,94 \mathrm{a}$ & $2,42 \mathrm{a}$ \\
\hline 7Sc,SP/0,5Av,SD & $3,1^{(2)} \mathrm{c}$ & $0,8 \mathrm{~b}$ & 0,26 & $22 \mathrm{~b}$ & $20 \mathrm{a}$ & $2,80 \mathrm{~b}$ & $1,51 \mathrm{~b}$ \\
\hline 4Av - Mi,SD/3,5Sc,SP & $0 \mathrm{~d}$ & $0 \mathrm{c}$ & - & $22 \mathrm{~b}$ & $20 \mathrm{a}$ & $2,10 \mathrm{~b}$ & $0,88 \mathrm{~b}$ \\
\hline
\end{tabular}

${ }^{(1)}$ Massa seca de raízes mortas na camada de 10 a $20 \mathrm{~cm}$ do solo/massa seca de raízes mortas na camada de 0 a $10 \mathrm{~cm} .{ }^{(2)}$ Raízes de aveia-preta. ${ }^{(3)}$ Raízes de ervilhaca. Valores na coluna seguidos da mesma letra não diferem entre si pelo teste de Duncan a $5 \%$. 
Quadro 3. Tipo, condição, material seco e percentagem de cobertura por resíduo cultural e índice de rugosidade (IR) superficial do solo antes da realização dos testes de erosão com chuva simulada (T1, T2 e T3) nas seqüências culturais estudadas

\begin{tabular}{|c|c|c|c|c|c|}
\hline Seqüência cultural & $\begin{array}{l}\text { Tipo de } \\
\text { resíduo }\end{array}$ & $\begin{array}{l}\text { Condição do } \\
\text { resíduo }\end{array}$ & $\begin{array}{l}\text { Massa de } \\
\text { resíduo }\end{array}$ & $\begin{array}{c}\text { Cobertura do } \\
\text { solo }\end{array}$ & IR \\
\hline & & & $\mathrm{Mg} \mathrm{ha}{ }^{-1}$ & $\%$ & $\mathrm{~cm}$ \\
\hline & \multicolumn{5}{|c|}{ T1 - solo não -mobilizado e coberto } \\
\hline 4Av-Mi,SD/3,5Av-Mt,SD & Aveia -preta & fresco & $12,2 \mathrm{a}$ & $100 \mathrm{a}$ & $0,059 \mathrm{a}$ \\
\hline $4 \mathrm{Sc}, \mathrm{SP} / 3,5 \mathrm{Er} \quad-\mathrm{Fm}, \mathrm{SD}$ & Ervilhaca & fresco & $3,5 \mathrm{c}$ & $82 \mathrm{~b}$ & $0,049 \mathrm{a}$ \\
\hline 7Sc,SP/0,5Av,SD & Aveia -preta & fresco & $8,1 \mathrm{~b}$ & $97 \mathrm{a}$ & $0,057 \mathrm{a}$ \\
\hline $4 \mathrm{Av}-\mathrm{Mi}, \mathrm{SD} / 3,5 \mathrm{Sc}, \mathrm{SP}$ & Milheto & velho $^{(1)}$ & $3,4 \mathrm{c}$ & $80 \mathrm{~b}$ & $0,025 \mathrm{a}$ \\
\hline \multicolumn{6}{|c|}{$\mathrm{T} 2$ - solo não-mobilizado e descoberto } \\
\hline 4Av-Mi,SD/3,5Av-Mt,SD & Aveia -preta & removido & - & 0 & $0,059 \mathrm{a}$ \\
\hline 4Sc,SP/ 3,5Er - Fm,SD & Ervilhaca & removido & - & 0 & $0,049 \mathrm{a}$ \\
\hline 7Sc,SP/0,5Av,SD & Aveia -preta & removido & - & 0 & $0,057 \mathrm{a}$ \\
\hline $4 \mathrm{Av}-\mathrm{Mi}, \mathrm{SD} / 3,5 \mathrm{Sc}, \mathrm{SP}$ & Milheto & removido & - & 0 & $0,025 \mathrm{a}$ \\
\hline \multicolumn{6}{|c|}{ T3 - solo recém - mobilizado e descoberto } \\
\hline 4Av-Mi,SD/3,5Av-Mt,SD & Aveia -preta & removido & - & 0 & $1,082 \mathrm{a}$ \\
\hline 4Sc,SP/3,5Er - Fm,SD & Ervilhaca & removido & - & 0 & $0,975 \mathrm{~b}$ \\
\hline 7Sc,SP/0,5Av,SD & Aveia -preta & removido & - & 0 & $0,652 \mathrm{c}$ \\
\hline $4 \mathrm{Av}-\mathrm{Mi}, \mathrm{SD} / 3,5 \mathrm{Sc}, \mathrm{SP}$ & Milheto & removido & - & 0 & $0,413 \mathrm{~d}$ \\
\hline
\end{tabular}

(1) Exposto às ações do tempo e microrganismos do solo durante 12 meses. Valores na coluna seguidos da mesma letra não diferem entre si pelo teste de Duncan a $5 \%$.

de água da chuva na forma de enxurrada, observa-se que houve diferenças significativas entre as seqüências culturais nos três testes de erosão com chuva simulada (T1, T2 e T3). Quanto à perda total de solo, a diferença entre as seqüências culturais foi estatisticamente significativa somente no segundo (T2) e no terceiro (T3) teste de chuva. Quando o solo de todos os tratamentos se encontrava na situação de nãomobilizado (superfície consolidada e praticamente lisa - testes de chuva T1 e T2), a seqüência cultural $4 \mathrm{Sc}, \mathrm{SP} / 3,5 \mathrm{Er}-\mathrm{Fm}, \mathrm{SD}$ foi a que apresentou maior valor de taxa constante de infiltração de água no solo e menor valor de perda total de água, seguida de perto pela identificada como $4 \mathrm{Av}-\mathrm{Mi}, \mathrm{SD} / 3,5 \mathrm{Av}-\mathrm{Mt}, \mathrm{SD}$, enquanto as identificadas como $7 \mathrm{Sc}, \mathrm{SP} / 0,5 \mathrm{Av}, \mathrm{SD}$ e 4Av-Mi,SD/3,5Sc,SP apresentaram os menores valores da primeira variável e os maiores da última, com resultados semelhantes entre si em relação a elas, independentemente da cobertura do solo por resíduo cultural. Esses resultados revelam a melhor condição física do solo para infiltrar água da chuva nas seqüências culturais com maior tempo no experimento. Já a mobilização do solo por meio do uso de grade, efetuada antes da realização do terceiro teste de chuva (T3), resultou na maior taxa constante de infiltração de água no solo e na menor perda total de água entre as observadas no estudo. Quanto à perda total de solo, ela foi a menor no primeiro teste de chuva (T1) em todas as seqüências culturais, devido à elevada cobertura do solo por resíduo cultural (Quadro 3), variando muito no segundo (T2) e no terceiro (T3) teste, ambos sem cobertura por resíduo cultural, em função do preparo do solo e da seqüência cultural.

$\mathrm{Na}$ figura 3, são apresentados os resultados da correlação da taxa constante de infiltração de água no solo com a massa de raízes mortas secas e com o diâmetro médio ponderado (DMP) de agregados. Observa-se que, no solo não-mobilizado (superfície consolidada e praticamente lisa), tanto coberto quanto descoberto (testes de chuva T1 e T2), esta correlação resultou em valores do coeficiente de determinação $\left(\mathrm{R}^{2}\right)$ relativamente altos e graus de ajuste dos modelos matemáticos significativos, tanto com a massa de raízes mortas secas quanto com o índice DMP. Na situação de solo recém-mobilizado (superfície solta e rugosa) e descoberto (teste de chuva T3), o preparo do solo com grade instantaneamente criou condições físicas adequadas para a infiltração de água. Dessa forma, tais condições se sobrepuseram ao efeito da massa de raízes mortas secas e do diâmetro médio ponderado de agregados no que diz respeito ao aumento da taxa constante de infiltração de água no solo, fazendo com que a correlação desta variável com as duas primeiras resultasse em valores de $\mathrm{R}^{2}$ muito baixos, sendo os ajuste dos modelos matemáticos não-significativos. 

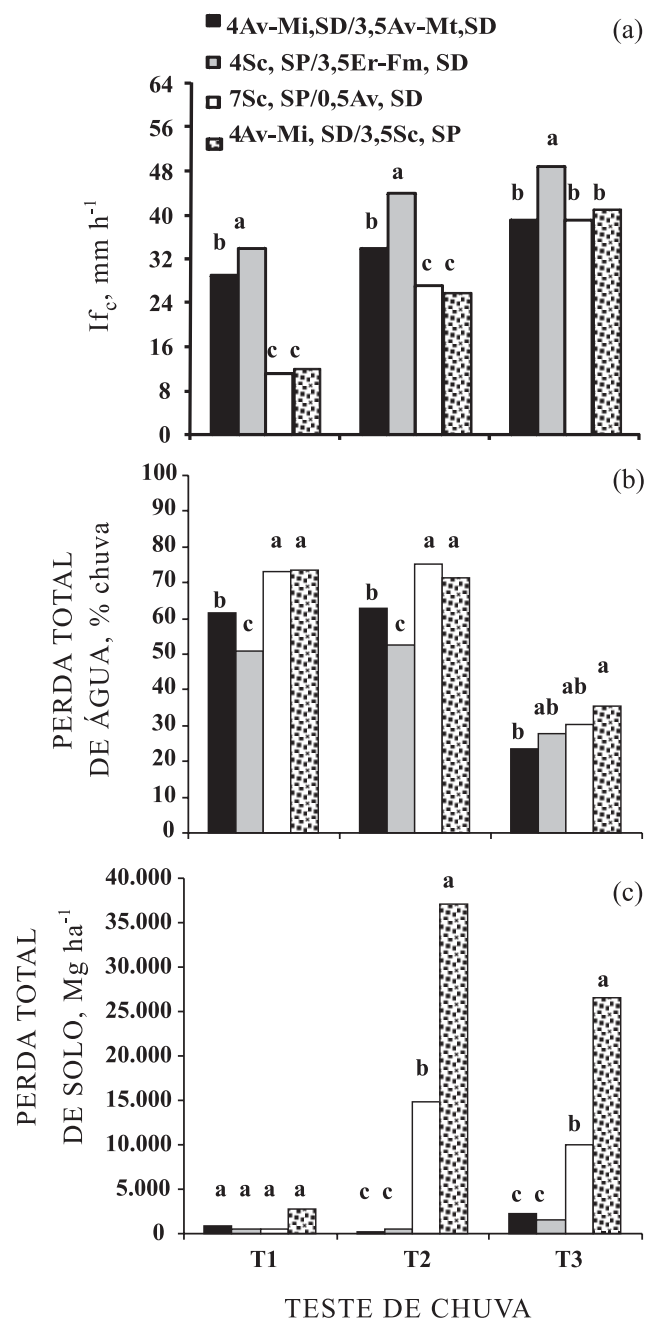

Figura 2. Taxa constante de infiltração de água no solo - If $f_{c}(a)$ perda total de água (b) e perda total de solo (c) nos testes de erosão com chuva simulada T1, T2 e T3, nas seqüências culturais estudadas (colunas sobrescritas com a mesma letra, num mesmo teste de chuva, não diferem entre si pelo teste de Duncan a $5 \%$ ).

Na figura 4, são apresentados os resultados da correlação da perda total de água da chuva na forma de enxurrada com a massa de raízes mortas secas e com o diâmetro médio ponderado (DMP) de agregados. Observa-se que esta correlação também resultou em valores do coeficiente de determinação $\left(R^{2}\right)$ relativamente altos, com os graus de ajuste dos modelos matemáticos significativos nas três situações avaliadas da camada superficial do solo. Claramente, percebe-se a diminuição da perda total de água com o aumento tanto da massa de raízes mortas secas (Figura 4a) quanto do diâmetro médio ponderado de agregados (Figura 4b).

$\mathrm{Na}$ figura 5 são apresentados os resultados da correlação da perda total de solo com a massa de raízes mortas secas e com o diâmetro médio ponderado (DMP) de agregados. Diferentemente da perda total de água, cuja correlação com as variáveis em pauta foi significativa nas três situações avaliadas da camada superficial do solo, a correlação da perda total de solo apresentou resultados significativos somente em duas situações (não foi significativa a correlação na situação de solo não-mobilizado - superfície consolidada e praticamente lisa - e coberto do teste T1). Assim, de modo geral, observa-se que a perda total de solo foi bastante diminuída com o aumento tanto da massa de raízes mortas secas quanto do diâmetro médio ponderado (DMP) de agregados. Ressalta-se que esta afirmação não se sustenta quando o solo se encontra com elevada cobertura superficial por resíduo cultural,
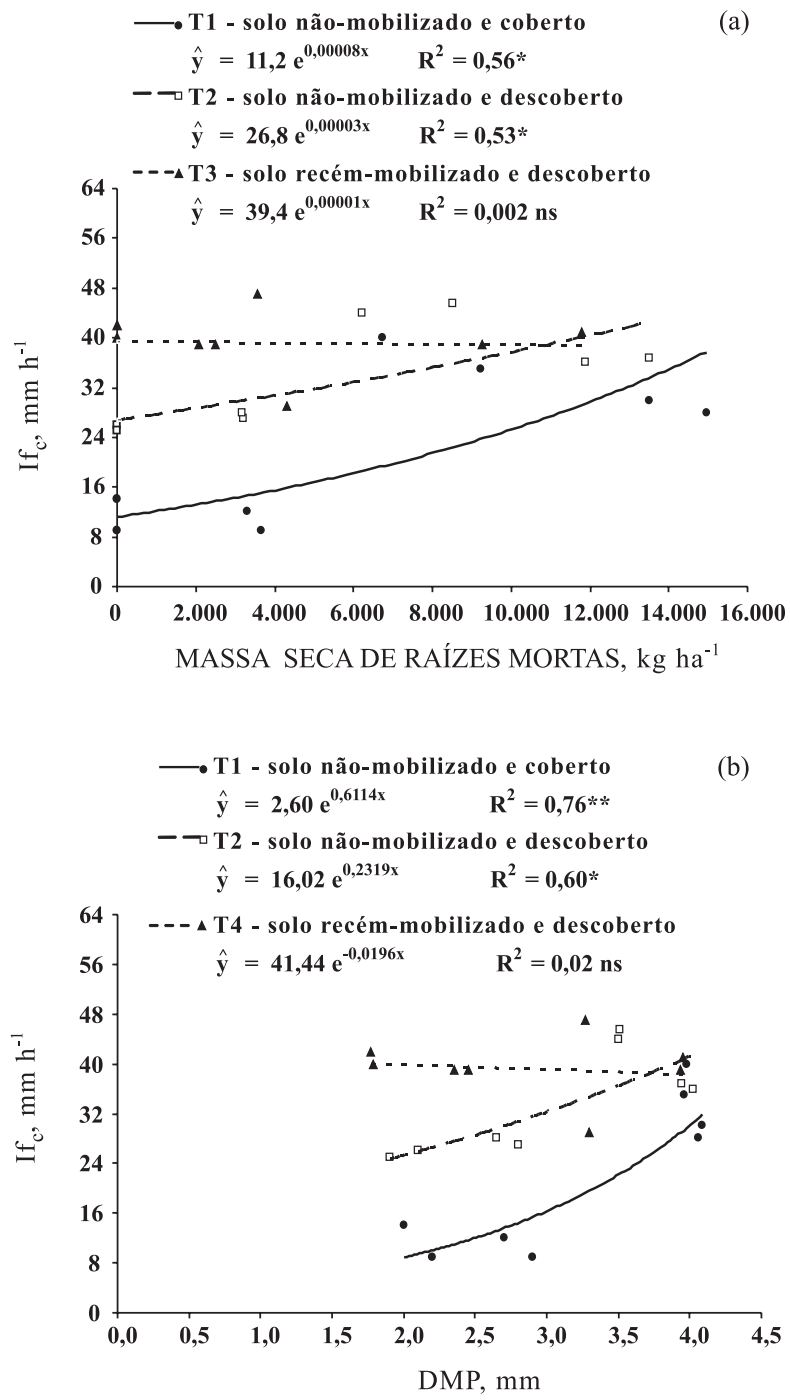

Figura 3. Relação da taxa constante de infiltração de água no solo - If $_{\mathbf{c}}$ - com a massa de raízes mortas secas (a) e com o diâmetro médio ponderado DMP - de agregados (b) na camada de 0 a $10 \mathrm{~cm}$, em distintas condições físicas da camada superficial do solo, independentemente das seqüências culturais estudadas. 


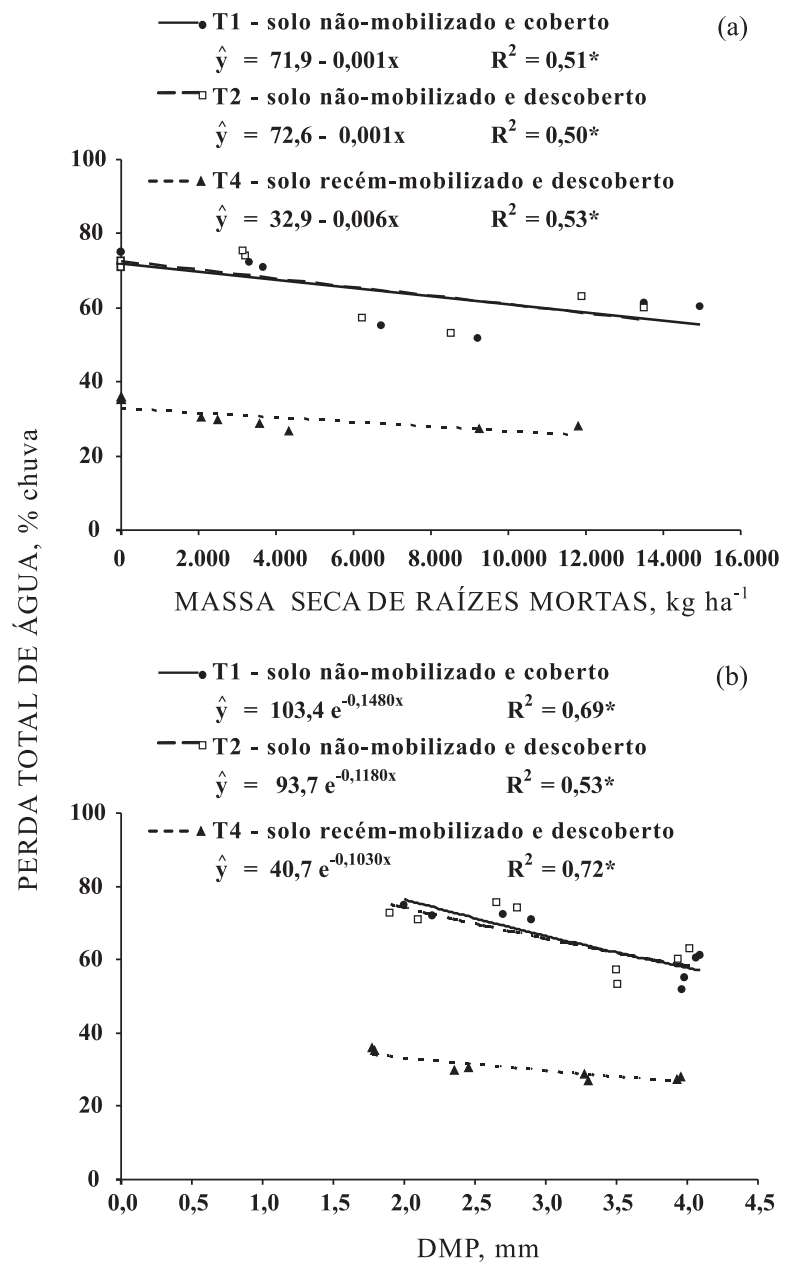

Figura 4. Relação da perda total de água com a massa de raízes mortas secas (a) e com o diâmetro médio ponderado - DMP - de agregados (b) na camada de 0 a $10 \mathrm{~cm}$, em distintas condições físicas da camada superficial do solo, independentemente das seqüências culturais estudadas.

como aconteceu no primeiro teste de chuva (T1). Neste teste, a grande cobertura do solo por resíduo cultural praticamente eliminou a desagregação das partículas do solo por impacto das gotas da chuva, fazendo com que a perda de solo fosse muito pequena, independentemente da massa seca de raízes mortas e do diâmetro médio ponderado de agregados (DMP). Nos testes subseqüentes (T2 e T3), entretanto a variação nos valores de DMP explicou melhor a variação nos valores de perda total de solo do que a variação nos valores de massa de raízes mortas secas. Observa-se ainda, na figura 5 , que a variação da perda total de solo foi explicada melhor, por qualquer uma das variáveis de manejo em consideração, em solo nãomobilizado (superfície consolidada e praticamente lisa) do segundo teste de chuva (T2) do que na situação de solo recém-mobilizado (superfície solta e rugosa) do terceiro teste (T3), ambos desprovidos de cobertura superficial por resíduo cultural.

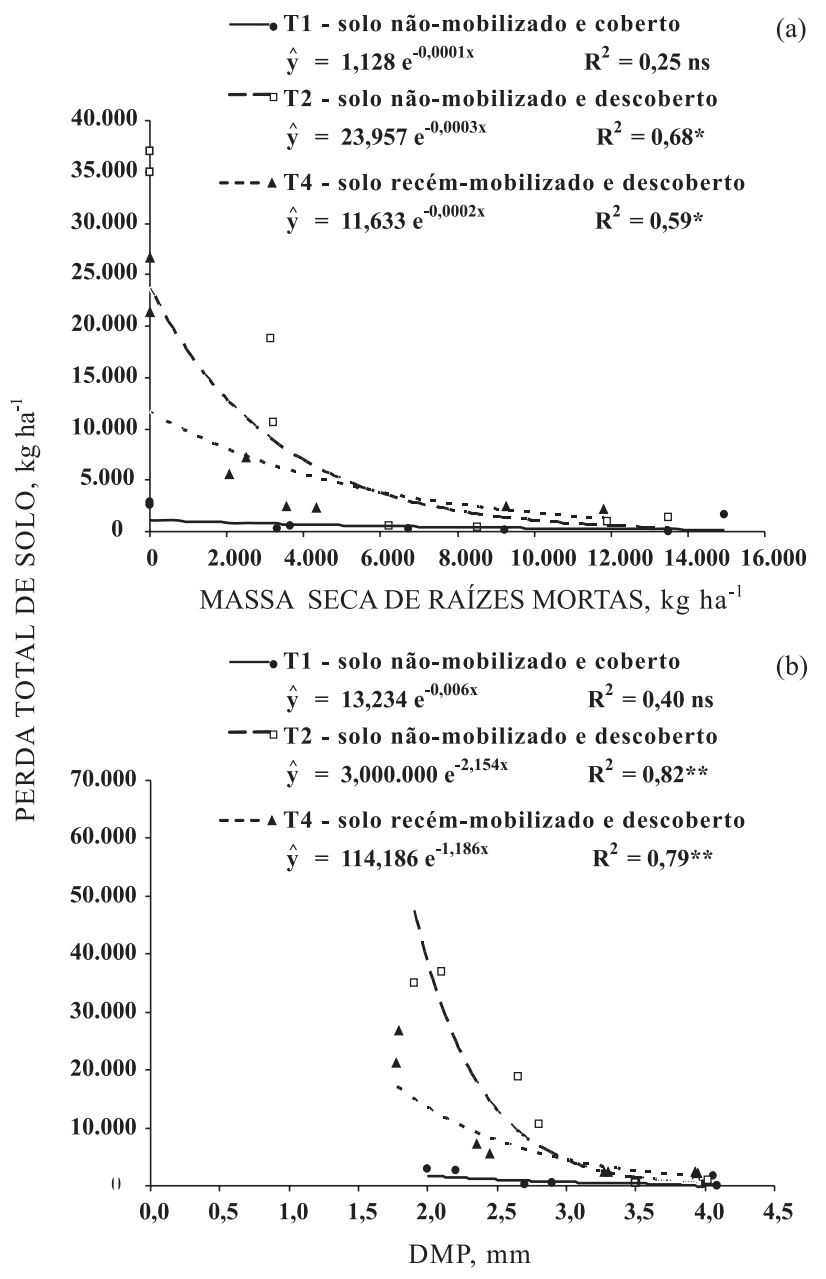

Figura 5. Relação da perda total de solo com a massa seca de raízes mortas (a) e com o diâmetro médio ponderado - DMP - de agregados (b) na camada de 0 a $10 \mathrm{~cm}$, em distintas condições físicas da camada superficial do solo, independentemente das seqüências culturais estudadas.

\section{CONCLUSÕES}

1. As condições físicas da camada superficial do solo favoráveis à infiltração de água, conseqüentemente à diminuição do escoamento superficial, mostraram-se distintas das que favoreceram sua resistência ao processo erosivo.

2. Para a infiltração de água, foram importantes a mobilização moderada do solo e o conseqüente aumento da sua rugosidade superficial, acompanhados de alta quantidade de massa de raízes mortas e de altos valores de diâmetro médio ponderado de agregados.

3. Para a resistência do solo à erosão foram importantes a presença de alta taxa de cobertura do solo por resíduo cultural e a consolidação da superfície do solo propiciada pela ausência de preparo. 


\section{LITERATURA CITADA}

ALBUQUERQUE, J.A.; CASSOL, E.A. \& REINERT, D.J. Relação entre a erodibilidade em entressulcos e estabilidade dos agregados. R. Bras. Ci. Solo, 24:141-151, 2000 .

AMADO, T.J.C.; COGO, N.P. \& LEVIEN, R. Eficácia relativa do manejo do resíduo cultural de soja na redução das perdas de solo por erosão hídrica. R. Bras. Ci. Solo, 13:251253, 1989.

BADELUCCI, M.P. Infiltração de água e perdas por erosão em diferentes métodos de melhoramento da pastagem nativa. Porto Alegre, Universidade Federal do Rio Grande do Sul, 1997. 137p. (Tese de Doutorado)

BURWELL, R.E.; ALLMARAS, R.R. \& AMEMIYA, M. A field measurement of total porosity and surface microrelief of soils. Soil Sci. Soc. Am. J., 27:696-700, 1963.

COGO, N.P. Effect of residue cover, tillage-induced roughness and slope length on erosion and related parameters. West Lafayette, Purdue University, 1981. 381p. (Tese de Doutorado)

COGO, N.P. \& STRECK, E.V. Surface and subsurface decomposition of a desiccated grass pasture biomass related to erosion and its prediction with RUSLE. R.Bras. Ci. Solo, 27:153-164, 2003.

COGO, N.P.; LEVIEN, R. \& VOLK, L.B.S. Indicadores de qualidade do solo: Aspectos relacionados à erosão hídrica pluvial e à mecanização tratorizada. In: CONGRESSO BRASILEIRO DE CIÊNCIA DO SOLO, 29., Ribeirão Preto, 2003. Anais. Viçosa, MG, Sociedade Brasileira de Ciência do Solo, 2003. CD-ROM.

COGO, N.P.; MOLDENHAUER, W.C. \& FOSTER, G.R. Effect of residue cover, tillage-induced roughness, and runoff velocity on size distribution of eroded soil aggregates. Soil Sci. Soc. Am. J., 47:1005-1008, 1983.

COGO, N.P.; MOLDENHAUER, W.C. \& FOSTER, G.R. Soil loss reductions from conservation tillage practices. Soil Sci. Soc. Am. J., 48:368-373, 1984.

EMPRESA BRASILEIRA DE PESQUISA AGROPECUÁRIA EMBRAPA. Recomendações gerais do encontro sobre o uso do simulador de chuva em pesquisa de conservação do solo no Brasil. In: ENCONTRO NACIONAL SOBRE PESQUISA DE EROSÃO COM SIMULADOR DE CHUVA, Londrina, 1975. Resumos. Londrina, IAPAR, 1975. p.107-120

EMPRESA BRASILEIRA DE PESQUISA AGROPECUÁRIA EMBRAPA. Sistema brasileiro de classificação de solos. 2.ed. Rio de Janeiro, Centro Nacional de Pesquisa de Solos, 2006. 412 p.

FISCHER, R.A. \& YATES, F. Tabelas estatísticas para biologia, medicina e agricultura. São Paulo, EDUSP, 1971. 150p.

HARTWIG, R.O. \& LAFLEN, J.M. A meterstick method for measuring crop residue cover. J. Soil Water Conserv., 33:90-91, 1978.
HUDSON, N.W. Soil conservation. 3.ed. Ames, Iowa State University Press, 1995. 391p.

LE BISSONNAIS, Y. Aggregate stability and assessment of soil crustability and erodibility: I. Theory and methodology. Eur. J. Soil Sci., 47:425-437, 1996.

LE BISSONNAIS, Y. \& ARROUYAS, D. Aggregate stability and erodibility: II. Application to humic loamy soils with various organic carbon contents. Eur. J. Soil Sci., 48:3949, 1997.

LOPES, P.R.C. Relações da erosão com tipos e quantidades de resíduos culturais espalhados uniformemente sobre o solo. Porto Alegre, Universidade Federal do Rio Grande do Sul, 1984. 116p. (Dissertação Mestrado)

RENARD, K.G.; FOSTER, G.R.; WEESIES, G.A.; McCOOL, D.K. \& YODER, D.C. Predicting soil erosion by water: A guide conservation planning with the revised universal soil loss equation (RUSLE). Washington, United States Department of Agriculture, 1997. (Agriculture Handbook, 8)

SILVA. I.F. Formação, estabilidade e qualidade de agregados do solo afetados pelo uso agrícola. Porto Alegre, Universidade Federal do Rio Grande do Sul, 1993. 126p. (Tese de Mestrado)

STRECK, E.V.; KÂMPF, N. \& KLAMT, E. Atualização da classificação taxonômica das unidades de mapeamento do levantamento de reconhecimento dos solos do estado do Rio Grande do Sul. Informativo da EMATER/RS. Série: solos. Porto Alegre, v.16, n.9, 5p. 1999.

SWANSON, N.P. A rotating-boom rainfall simulator. Transactions of the ASAE, 26:1738-1743, 1965.

TISDALL, J.M. \& OADES, J.M. Organic matter and waterstable aggregates in soil. Eur. J. Soil Sci., 33:141-163, 1982.

VOLK, L.B.S. Condições físicas da camada superficial do solo resultantes do seu manejo e indicadores de qualidade para redução da erosão hídrica e do escoamento superficial. Porto Alegre, Universidade Federal do Rio Grande do Sul, 2006. 148p. (Tese de Doutorado)

VOLK, L.B.S.; COGO, N.P. \& STRECK, E.V. Erosão hídrica influenciada por condições físicas de superfície e subsuperfície do solo resultantes do seu manejo, na ausência de cobertura vegetal. R. Bras. Ci. Solo, 28:763774,2004

WISCHMEIER, W.H. Conservation tillage to control water erosion. In: CONSERVATION TILLAGE CONFERENCE, 1973, Des Moines. Proceedings. Des Moines, 1973. p.133144.

WISCHMEIER, W.H. \& SMITH, D.D. Predicting rainfall erosion losses: A guide to conservation planning. Washington, United States Department of Agriculture, 1978. 58p. (Agriculture Handbook, 537)

YODER, R.E. A direct method of aggregate analysis of soils and a study of physical nature of erosion losses. J. Am. Soc. Agron., 28:337-351, 1936. 